Research Article

\title{
Intelligent Rural Tourism Environmental Suitability Evaluation System Based on a Wireless Sensor Network
}

\author{
Feng Ying $\mathbb{C}$ \\ International Business School, Heilongjiang International University, Harbin 150025, China \\ Correspondence should be addressed to Feng Ying; fengying@hiu.net.cn
}

Received 16 September 2021; Accepted 30 September 2021; Published 31 October 2021

Academic Editor: Guolong Shi

Copyright () 2021 Feng Ying. This is an open access article distributed under the Creative Commons Attribution License, which permits unrestricted use, distribution, and reproduction in any medium, provided the original work is properly cited.

\begin{abstract}
After years of vigorous development, the scale of rural tourism industry has gradually expanded throughout the country, and it has become an important means of coordinating urban and rural areas to drive farmers' incomes and get rich. Nowadays, the level of informatization is constantly improving, the construction of smart cities is constantly advancing, the personalized demand of tourists is increasingly strong, especially the rural tourist spots scattered in the vast countryside which have a great spatial breadth, and the traditional management method can no longer meet the needs of the source objects whose main travel mode is self-driving. Therefore, only when rural tourism develops in the direction of intelligence can it successfully realize the transformation and upgrading of rural tourism industry. This paper takes a rural tourism resort in a certain area as the research object and builds an intelligent rural tourism environmental suitability evaluation system with three criterion levels: natural geographic conditions, traffic environmental conditions, and tourism spatial conditions. The weight of each indicator layer is obtained through the analytic hierarchy process, and the reclassified raster data of indicators is weighted and superimposed on the ArcGIS operating platform to obtain the evaluation result of the environmental suitability of smart rural tourism. According to the results of suitability evaluation, the most suitable area is selected as the potential area of the intelligent rural tourism environment in a certain area. According to the natural and cultural tourism resource conditions in the block, the potential block is divided into functions. A comprehensive comparison of the suitability spatial differentiation map of the smart rural tourism environment in a certain area with the suitability spatial differentiation map of each subsystem can more clearly find that the suitability score of the economic development subsystem and the basic support subsystem is a county-level village in a certain area. Among them, the suitability of the rural economic development subsystem is similar to the distribution of the suitability of the smart rural tourism environment in a certain area; that is, it is positively correlated with the suitability of the smart rural tourism environment. Therefore, improving the level of rural economic development and increasing investment in the construction of a smart rural tourism environment play an important role in improving the level of public services and infrastructure coverage.
\end{abstract}

\section{Introduction}

At present, the tourism industry is gradually transforming and upgrading into a modern service industry and a strategic pillar industry, out of the scope of the traditional service industry [1]. With the continuous improvement of tourism market demand and the rapid development of information technology, the tourism industry has entered the era of smart tourism. At the same time, tourism management has also changed from a traditional single management model to a new model of "management + service." Therefore, tourism public services are gradually incorporated into the core functions of local government administrative bodies and become an important indicator of urban tourism satisfaction. Based on this background, smart tourism public service, a smart tourism public service centered on the integration and development of tourism public services and smart tourism, appears imminent and vital and has important theoretical innovation and practical dual values [2]. The construction of smart tourism is not only a requirement for comprehensively realizing tourism informatization but also a strategic choice to improve the city's comprehensive competitiveness 
and develop the tourism economy; and tourism public services, as an important basic support for the tourism industry, provide an important guarantee for the sustainable development of the tourism industry [3].

It is beneficial to improve the research foundation based on the related theories of tourism planning. From the perspective of tourism, regional tourism planning and development research includes two levels: single topic research and comprehensive development research, which complement each other, and regional tourism comprehensive planning and development research is based on a single topic research [4]. Therefore, taking the development of village-based scenic spots as an example, through the principle of system theory, we will study and analyze the development elements of village-based scenic spots in the development process, such as resources, environment, humanities, industries, and human settlements, and understand their internal structure and causes. At the same time, reasonable allocation and utilization of effective resources in the villages should be carried out to give full play to the huge potential of resources and provide theoretical cornerstones and a basis for regional development [5]. The development and research of villageoriented scenic spots should not only pay attention to the research on the cultural level but also pay attention to the interrelationship and mutual application with landscape, planning, architecture, geography, and other disciplines. It can improve the theoretical research on the evaluation of the development of village-based scenic spots to avoid decision-makers from embarking on the detour of eagerness for quick success and short gains and only pursuing superficial performance and truly achieve objective and fair evaluation [6].

This paper designs the overall structure of the hardware monitoring system, which is composed of a multisensor system. The equipment, chips, and working parameters of the RFID subsystem are selected, and the working process of the system is analyzed; the topology, hardware composition, and sensor node design adopted by the multisensor network system are described in detail. This study takes a certain area as the research area, through consulting literature and consulting related experts, establishes a smart rural tourism environmental suitability evaluation system, uses the analytic hierarchy process to determine the weight of each indicator, and obtains the evaluation of the suitability of rural tourism development through overlay analysis. According to the evaluation results, the potential areas of rural tourism resorts in a certain area are determined. A series of specific evaluation techniques and methods such as index selection, index weight calculation, index assignment, and index synthesis are used to construct an intelligent rural tourism environmental suitability evaluation system. We implement the completed evaluation system into specific practical cases and propose corresponding suitability optimization strategies based on the characteristics of different problems in each village. This article breaks through the constraints of the existing spatial scales of smart rural tourism environmental evaluation research and implements the smart rural tourism environmental suitability evaluation to the specific rural spatial category, which can provide a certain reference for future smart rural tourism environmental improvement research.

\section{Related Work}

The China National Tourism Administration launched the "Golden Tourism Project," which strongly promoted the development of informatized tourism and attracted the attention of people at home and abroad [7]. The Ministry of Science and Technology of the People's Republic of China launched the "Smart City" project, first conducting pilot experiments on smart city construction in Wuhan and Shenzhen. In the new five-year plan, the National Tourism Administration advocated the development of a "smart tourism" plan, designated Zhenjiang in Jiangsu Province as the "national smart tourism service center," and identified 17 other "national smart tourism pilot cities." Shanghai provides consumers with the "iTravels" service that relies on the smart mobile client, including various intelligent guidance services; Beijing provides tourists with self-service ticket checking through the high-tech network identified by $\mathrm{QR}$ codes $[8,9]$. The famous Wuyi Mountain provides a portable travel system that allows tourists to use mobile terminals to collect various service messages around them in real time. Hong Kong and Macau in China have a lot of experience in the use of smart tourism service platform systems. For example, the free travel planning program on the official website of the Hong Kong Tourism Board allows tourists to refer to various navigation maps on the Internet and plan their itinerary according to their personal preferences. In Macau, different groups of people are classified and screened, and various tourist maps are pushed [10]. Although the digitalization of tourism in our country is progressing swiftly, it is still a weak link from the perspective of the service industry. The fundamental reason is the inconsistent digitalization process, weak overall technological capabilities, lack of professional talents in key areas, lack of a unified service sharing mechanism, and delays in updating service information and data in various regions.

In recent years, domestic topics related to leisure agriculture have become a hot topic, and there are many research results, but in terms of rural tourism development evaluation, there are relatively few related studies [11]. From the perspective of agricultural tourism development evaluation research alone, the current domestic research hotspots are mainly concentrated in the two fields of ecological agriculture and sightseeing agriculture [12]. They took Jiujiang sightseeing agricultural tourism resources as an example and used the analytic hierarchy process to evaluate Jiujiang agricultural tourism resources from the three levels of resource conditions, development conditions, and management conditions, trying to provide assistance for the development of Jiujiang sightseeing agricultural tourism [13]. Relevant scholars adopted multidisciplinary theories, an innovative and improved analytic hierarchy process, divided three project layers at the same time, and constructed a more complete ecological agricultural tourism resource evaluation system [14]. Relevant scholars take the value of Fujian ecoagricultural tourism as the research object and use 
multidisciplinary theories such as ecology, agriculture, tourism, geography, society, and psychology to construct an evaluation index system for Fujian ecoagricultural tourism resources from the two levels of tourist attraction and development conditions [15]. In terms of the evaluation of leisure agricultural tourism resources, from the perspective of paper retrieval, although there are many research results on leisure agriculture, there are fewer references for the evaluation of leisure agricultural tourism resources. Relevant scholars took the leisure agriculture of Fujian Province as an example and constructed the six index project layers of environmental characteristics, product characteristics, management level, infrastructure construction, behavioral experience, and emotional experience $[16,17]$. There are 25 indicators to evaluate the leisure agriculture of Fujian Province. The innovation of this research lies in the establishment of an evaluation index system for leisure agriculture from the six aspects of environment, operation, products, facilities, behavior, and emotion, which is highly feasible and operability, and provides support for the development of the leisure agriculture evaluation system [18-20].

With the deepening of the perspectives and fields of rural tourism research, rural tourism has become a category of multidisciplinary integration. Aiming at the feasibility and necessity of rural tourism, it proves that the development of rural tourism is inseparable from sustainable development. Through the research and analysis of the national urban-rural coordination policy, the importance of rural imagery is proposed, and it is believed that to solve the current core problems of rural settlement tourism, it is necessary to look forward with a sustainable perspective. The concept of "global tourism" was elaborated, and it was believed that global tourism should fully explore tourism resources with the joint efforts of all walks of life and all participants and carry out historic innovations for the purpose of satisfying tourists' needs. The concept of global tourism is expounded. It is pointed out that global tourism is in a certain area, with tourism as the dominant industry, through comprehensive and systematic optimization and improvement of economic and social resources in the region. The organic integration of resources is a new model of taking the big with the small. Successful global tourism must bring about an overall improvement in the quality of local tourism.

\section{The Design of the Intelligent Rural Tourism Environment Monitoring System Based on a Wireless Sensor Network}

3.1. The Overall Composition of the System. The system is composed of two parts: RFID system and multisensor system, which mainly realizes data collection function. The data that needs to be collected includes tourist geographic location information, historical cultural relic location information, and temperature, humidity, and wind data information in key areas. Among them, the location information of tourists and cultural relics is collected through the RFID system; the temperature, humidity, and wind information are collected through the multisensor system. The overall composition is shown in Figure 1.

3.2. Multisensor System Design. A multisensor network is a network system composed of multiple sensor nodes distributed in certain areas based on a certain coverage requirement. By connecting various types of sensors, this system accurately and real-timely transmits and aggregates the designated data information in a distributed environment to the computer management terminal by means of signals. It uses the management terminal to realize the control and management of the wireless sensor network and related facilities, thereby completing the required application services. This system collects temperature, humidity, and wind speed data through sensing devices and uses ZigBee technology to build a wireless sensor network to transmit data information.

3.2.1. ZigBee Wireless Ad Hoc Network Technology. ZigBee is synonymous with IEEE 802.15.4 protocol. The technology stipulated in this agreement is a short-distance, low-power wireless communication technology, mainly suitable for automatic control and remote control, and can be embedded in various devices. The ZigBee wireless network can use three frequency bands, namely, the $2.4 \mathrm{GHz}$ ISM frequency band with 16 channels, the European $868 \mathrm{MHz}$ frequency band with 1 channel, and the US $915 \mathrm{MHz}$ frequency band with 10 channels. China uses the $2.4 \mathrm{GHz}$ frequency band with a bandwidth of $250 \mathrm{kHz}$, which is suitable for sensor data collection and control data transmission.

ZigBee adopts a self-organizing network communication method. Through automatic search, ZigBee network modules within the communication range can quickly form a mutually connected wireless network. When the modules move, the Unicom relationship will also change, and the modules will reestablish the relationship by searching for the contact person and refresh the network.

3.2.2. Wireless Sensor Network Structure. ZigBee defines three basic topological structures: star topological structure, clustered topological structure, and meshed topological structure. The star-shaped structure consumes less energy and is simple to deploy but has poor ductility; the meshshaped structure has high reliability but high energy consumption; the cluster-shaped structure has the advantages of both low energy consumption and good scalability. At the same time, because the scenic spot has a wide monitoring range, the number of nodes and communication range are limited, and it needs to be deployed in key areas and remote spots in the scenic spot, and the cluster-shaped structure is selected in the scenic spot weather information monitoring system to arrange the nodes. The ZigBee wireless sensor network designed by the system is composed of a coordinator, router, and sensor node. The sensor node is responsible for collecting and sending data; the router plays a relay role in the middle; the coordinator is responsible for data collection, also known as the collection node.

3.2.3. Sensor Node Design. The sensor node model is mainly composed of a processor, sensor, ZigBee transceiver, and power module. The processor is divided into two parts: a 


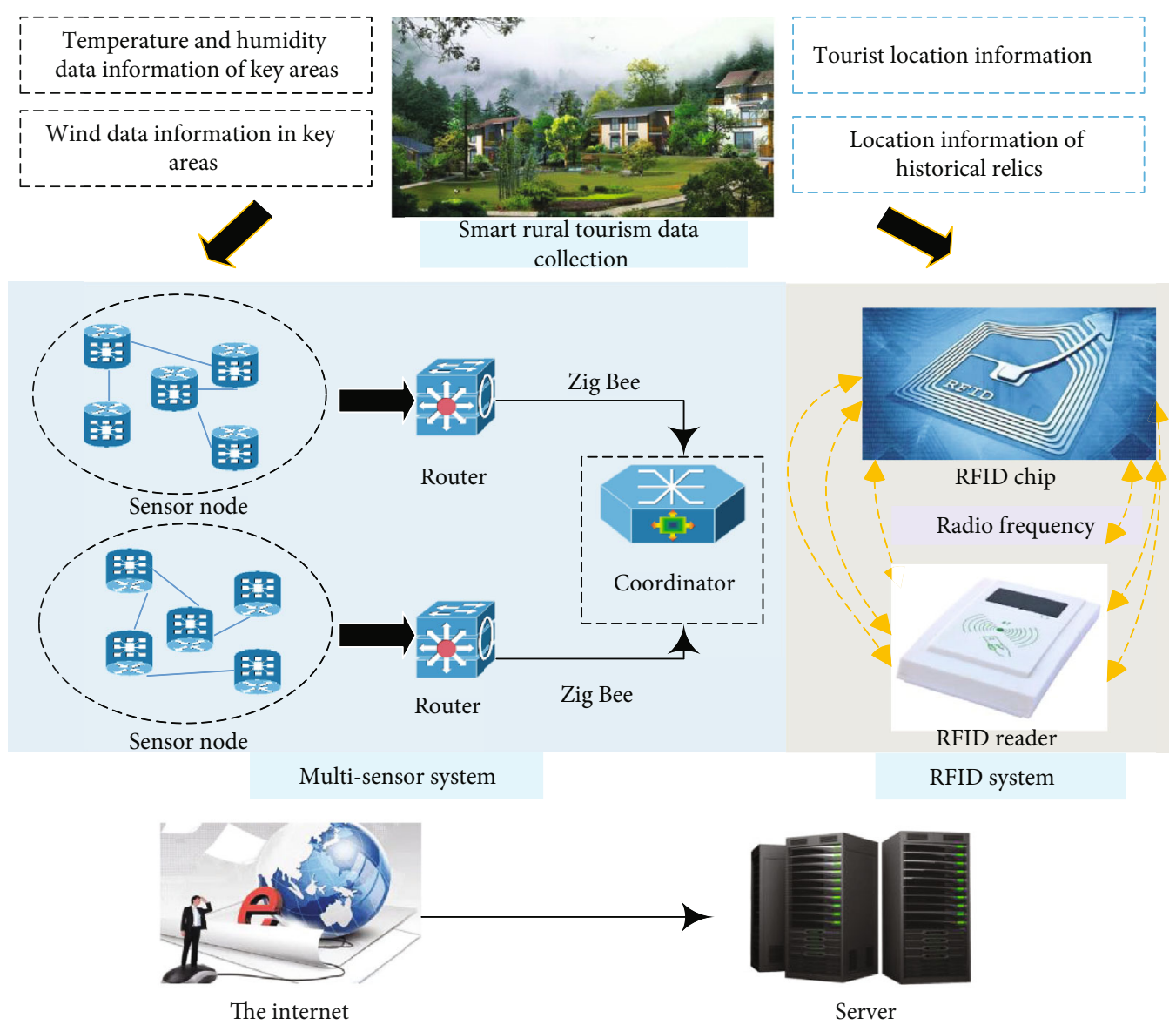

FIgURE 1: Intelligent rural tourism environment monitoring system.

microcontrol unit and a memory. The microcontrol unit is responsible for processing the data collected by the sensor and management and control information. The memory is used to store sensor and routing information; the sensor is used to collect various sensor information in the designated area. The transceiver is used to transmit and receive data wirelessly. The sensor node actually used in the system is mainly composed of the CC2430 module, sensor module, and power supply equipment. The hardware structure of the ZigBee sensor node is shown in Figure 2.

The CC series chips produced by TI-Chipcon Company used in the system have better wireless communication capabilities. The radiofrequency chip CC2430 integrates the ZigBee radiofrequency (RF) front end, memory, and microcontroller and is made with a $0.18 \mu \mathrm{m}$ CMOS process. The current consumption in the receiving and transmitting modes is lower than $27 \mathrm{~mA}$ or $25 \mathrm{~mA}$, and it is in sleep mode. The mode switch to the active mode has an ultrashort delay. Therefore, the CC2430 chip is particularly suitable for applications that require a long battery life.

The ZigBee wireless ad hoc network has good selfhealing ability and can automatically adjust the mobile or faulty nodes in the network structure, and the system can still work normally without staff intervention. Therefore, the ZigBee network shows good applicability in the scenic spot monitoring and management system.

\section{Evaluation of Environmental Suitability for Smart Rural Tourism}

4.1. Selection Method of Evaluation Indicators. A certain area is a typical hilly terrain, so it is necessary to select appropriate factors that affect rural tourism and vacation according to the characteristics of GIS spatial analysis. There are many factors that affect the layout of rural vacation tourism in hilly terrain, and different factors have different impacts. At present, rural tourism resorts are not supported by scientific and technological means before planning, and they rely too much on subjective judgments of experts, which are prone to problems such as unreasonable landscape planning, poor environmental stability of project site selection, and improper functional layout. Therefore, it is necessary to objectively, carefully, accurately, and comprehensively select influencing factors, focusing on the analysis of factors that highlight regional characteristics and have a greater impact on tourism planning.

4.1.1. Systematic. The selected indicators should meet the requirements of the comprehensive evaluation of rural tourism resorts. The evaluation indicator system should be constructed scientifically and reasonably, and various factors should be selected from as many aspects and wide areas as possible, such as comprehensive analysis of social, economic, 


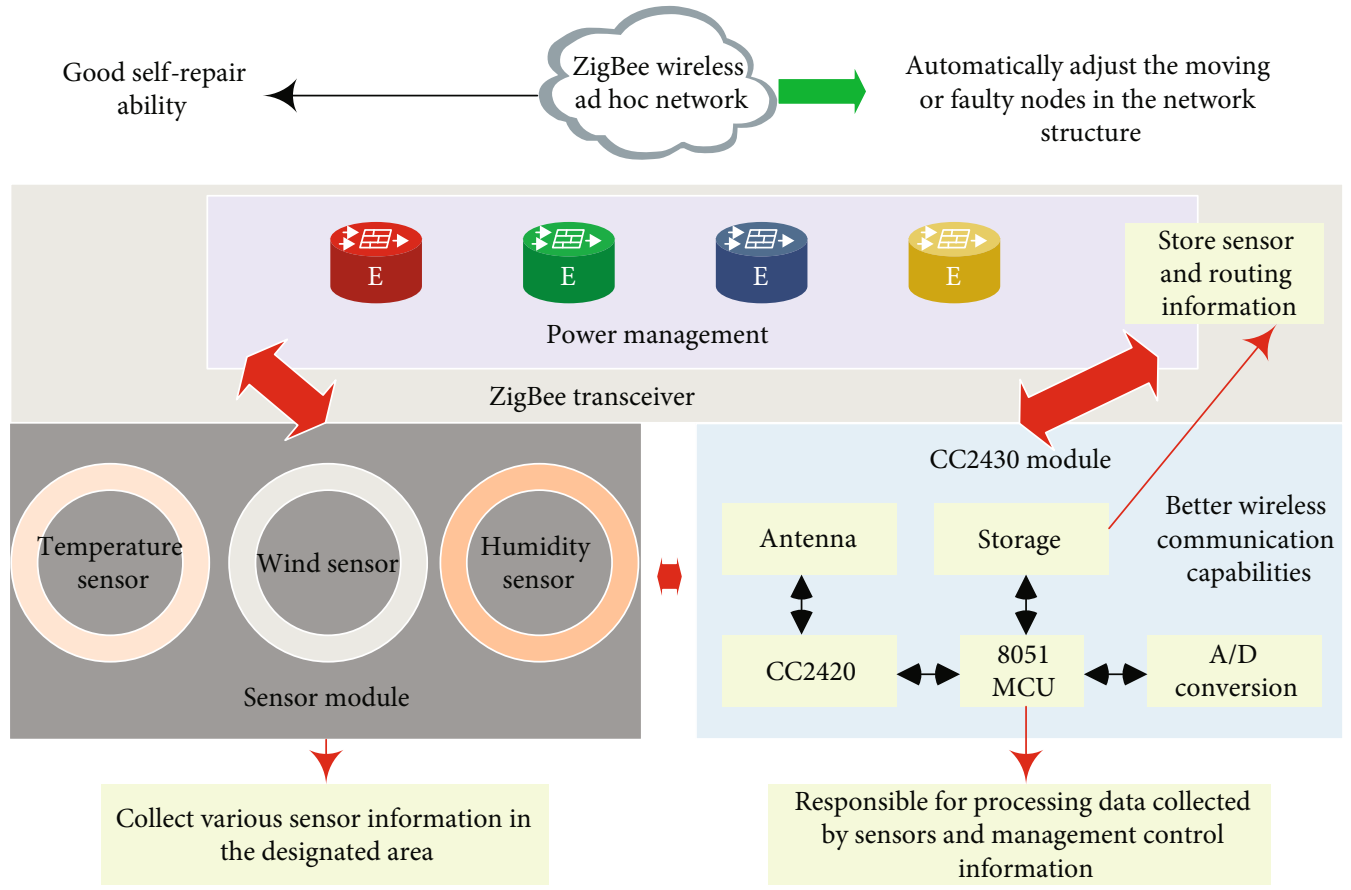

Figure 2: ZigBee sensor node composition.

environmental, and natural aspects. Each index is not only an indispensable link of the evaluation system but also can be combined to form a systematic and complete evaluation closed loop.

4.1.2. Ecological. Ecology is the most basic theme of rural tourism. The hilly area has special terrain and high sensitivity to the ecological environment. Rural tourism and vacation are a prolific and integrated emerging business, a complex ecosystem that encompasses nature, economy, and society. The internal organization is complex, information dissemination and conversion are frequent, and interdependence is strong. Therefore, when choosing the influencing factors of rural tourism resorts, it is necessary to fully consider the surrounding ecological environment factors, scientifically use land resources on the basis of maintaining the original environment, not blindly pursue economic benefits at the expense of the ecological environment, and achieve a natural balance. The balance between demand and optimal return meets the ecological requirements of rural tourism.

4.1.3. Operability. A comprehensive evaluation system generally needs sufficient indicators as support. You make a reasonable choice based on the timeliness and operability of the indicators. That is, information obtained under the current alternative channels will not reflect the previous situation due to the extension of the time limit. Therefore, for the reasonable development of evaluation work, the operability and timeliness of the indicators are very important.

\subsection{Quantitative Classification of Evaluation Indicators}

4.2.1. The Proximity of the Scenic Spot. The surrounding villages of the scenic spot are inseparable from the scenic spot itself. The surrounding villages have a high degree of similarity in terms of cultural context, geographical context, and local perception. The surrounding villages can cultivate cultural soil for the development of rural tourism and vacation and enrich the attraction of the scenic spot. The infrastructure and tourist dividends shared with the surrounding villages enable the unique tourism resources of the villages to complement and interact with the resources of the scenic spots and promote good chemical reactions through the accumulation of tourism resources. When selecting and developing rural tourist resorts, the spatial relationship with surrounding scenic spots should be considered. Generally speaking, the closer the rural tourist resorts are to the existing scenic spots, the higher their development suitability and the greater the potential index. This article divides the buffer distance of the scenic spot into four levels: the most suitable $(\leq 800 \mathrm{~m})$, more suitable $(800-1300 \mathrm{~m})$, generally suitable $(1300-1800 \mathrm{~m})$, and unsuitable $(>1800 \mathrm{~m})$. The expression is as follows:

$$
f(x)= \begin{cases}1 & (x \geq 1800 \mathrm{~m}) \\ 2 & (1300 \mathrm{~m}<x<1800 \mathrm{~m}), \\ 3 & (800 \mathrm{~m}<x \leq 1300 \mathrm{~m}), \\ 4 & (x \leq 800 \mathrm{~m})\end{cases}
$$

4.2.2. The Proximity of Cultural and Leisure Facilities. Parks, museums, memorials, and other places are the main places for local residents to carry out cultural and leisure activities. For holidaymakers, these cultural and leisure places often condense the cultural essence of a place. They are the mobile storage of local cultural heritage, which can reflect the local 
culture. The local customs facilitate foreign tourists to quickly understand the local history and culture and taste the local leisure and vacation living atmosphere. At the same time, these places have a certain radiating effect on the rural tourism projects to be developed. Rural tourism resorts often choose places where there are more cultural and leisure spots so that tourists can experience the local culture nearby. The closer the area is to cultural and leisure facilities, the greater the development potential and the higher the suitability. This article divides the distance from the cultural leisure point into four levels: the most suitable $(\leq 700 \mathrm{~m})$, more suitable $(700-1200 \mathrm{~m})$, generally suitable $(1200-1700 \mathrm{~m})$, and unsuitable $(>1700 \mathrm{~m})$, and we assign values to this index. The expression of quantization processing is as follows:

$$
f(x)= \begin{cases}1 & (x \geq 1700 \mathrm{~m}) \\ 2 & (1200 \mathrm{~m}<x<1700 \mathrm{~m}) \\ 3 & (700 \mathrm{~m}<x \leq 1200 \mathrm{~m}) \\ 4 & (x \leq 700 \mathrm{~m})\end{cases}
$$

4.2.3. Water Distance. Water is the basic element that constitutes the human living environment and an important foundation for maintaining ecological balance and a beautiful environment. Rivers and lakes regulate the water vapor content in the atmosphere and determine the comfort of the human body. At the same time, the regional civilization, river culture, and beautiful natural scenery they carry are valuable tourism resources, and they are a good place for people to visit and relax. The study area contains abundant water resources. The development and utilization of rivers and lakes have a huge promotion effect on the development of rural tourism. According to the areas with closer water resources, the more resource dividends can be enjoyed, and the higher the value of development. According to the dense water network in the study area, this paper appropriately adjusts the buffer distance of the water area, eliminates the smaller pond water surface, and divides the water area buffer distance into the most suitable $(\leq 100 \mathrm{~m})$, more suitable (100$600 \mathrm{~m})$, generally suitable $(600 \mathrm{~m}-1100 \mathrm{~m})$, and unsuitable $(>1100 \mathrm{~m})$. The expression for quantitative processing of this index is as follows:

$$
f(x)= \begin{cases}1 & (x \geq 1100 \mathrm{~m}) \\ 2 & (600 \mathrm{~m}<x<1100 \mathrm{~m}) \\ 3 & (100 \mathrm{~m}<x \leq 600 \mathrm{~m}) \\ 4 & (x \leq 100 \mathrm{~m})\end{cases}
$$

\subsection{Calculation of Evaluation Index Weight}

4.3.1. Construct a Judgment Matrix. By inviting experts to score the weights in pairs after the hierarchical model is established, the values 1-9 and their reciprocal are used as the measurement scale value. The higher the score indicates that the horizontal index is more important than the corresponding vertical index. The calculation process of the eval- uation index weight of the analytic hierarchy process is shown in Figure 3.

$$
A=\left[\begin{array}{cccc}
a_{11} & a_{12} & \cdots & a_{1 n} \\
a_{21} & a_{22} & \cdots & a_{2 n} \\
\vdots & \vdots & \vdots & \vdots \\
a_{n 1} & a_{n 2} & \cdots & a_{n n}
\end{array}\right]
$$

In the formula, aij must satisfy

$$
\begin{gathered}
a_{i j}=\left(a_{j i}\right)^{-1}, \quad i, j=1,2,3, \cdots, n, i \neq j, \\
a_{i j}=-1, \quad i=j .
\end{gathered}
$$

The matrix has the characteristics of positive value, reciprocity, basic consistency, etc. Table 1 is the meaning of its importance.

4.3.2. Calculate the Weight of Each Index and the Largest Characteristic Root. In this paper, the square root method is used to calculate the weights $w_{i}$ of the criterion layer and the index layer, respectively. We calculate the product of the elements of each row in each matrix:

$$
M_{i}=\prod_{i=j}^{n} a_{i j}, \quad i=1,2,3, \cdots, n
$$

Calculate the $n$th root of the element $M_{i}$ in each row:

$$
W_{i}=M_{i}^{1 / n}, \quad i=1,2,3, \cdots, n
$$

Normalize the calculated $W$ to get its weight value:

$$
W=\frac{w_{i}}{\left(\prod_{i=1}^{n}\left(w_{i} \bullet w_{i+1}\right)\right)}
$$

The maximum eigenvalue of the matrix is

$$
\lambda_{\max }=\prod_{i=1}^{n} \frac{(A W)_{j}}{n W_{j}}
$$

4.3.3. Consistency Test of the Judgment Matrix. Due to the complexity of the evaluation indicators and the subjective nature of the scoring of pairwise comparisons, expert scoring cannot ensure the consistency of the results. Therefore, the consistency of the scoring result matrix needs to be checked to avoid constructing a contradictory judgment matrix. The formula for calculating the consistency ratio $(\mathrm{CR})$ is as follows:

$$
\mathrm{CR}=\frac{\mathrm{CI}}{\mathrm{RI}}
$$




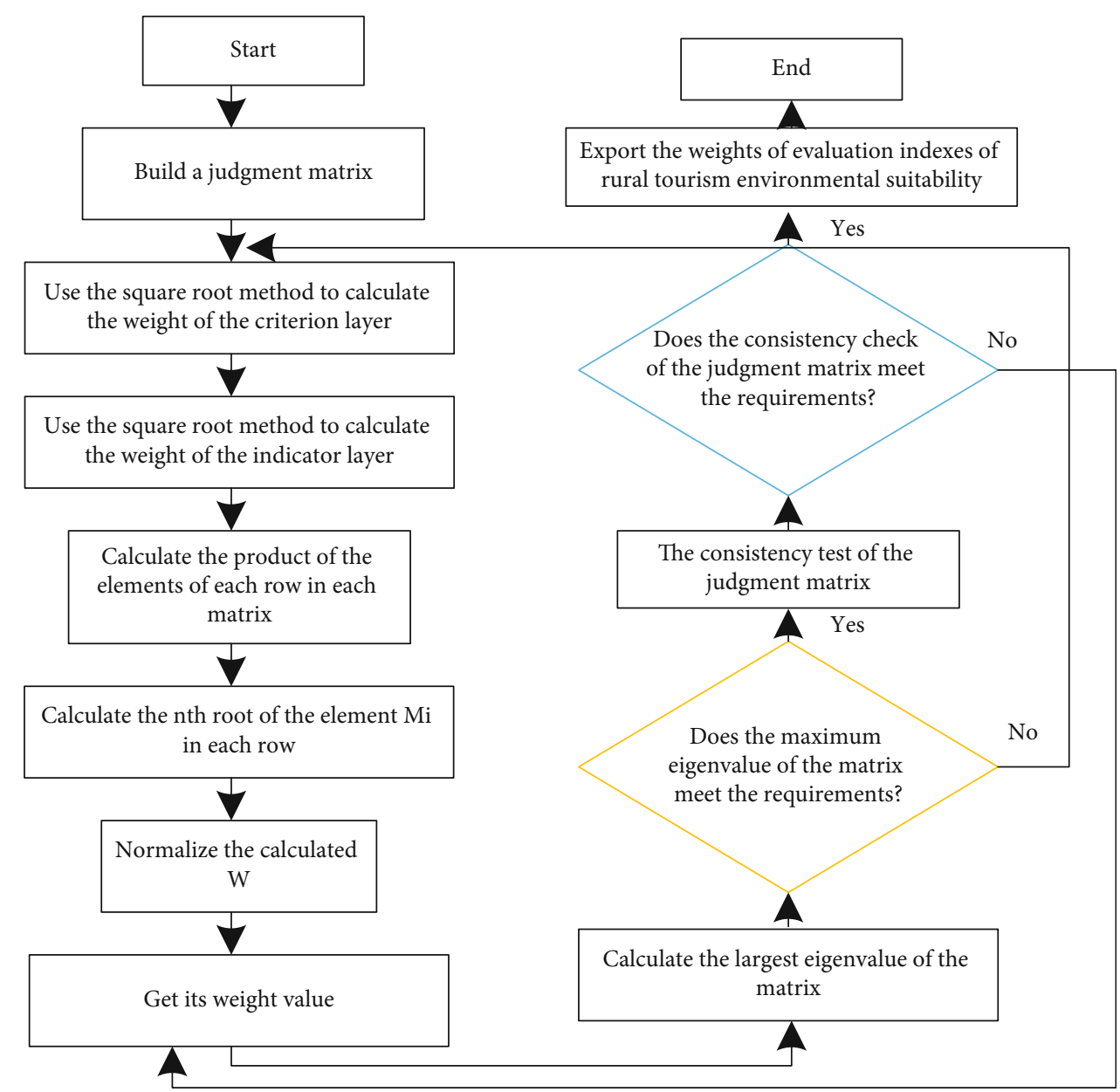

FIGURE 3: Analytic hierarchy process evaluation index weight calculation process.

TABLE 1: The meaning of the judgment matrix scale.

\begin{tabular}{l} 
Scaling \\
\hline 2 \\
4 \\
6 \\
8 \\
1 \\
$3,5,7,9 \quad$ Indicates that the elements are of equal importance compared to each other \\
Indicates that the elements are compared with each other; the former is slightly more important than the latter \\
Indicates that the elements are compared with each other; the former is more important than the latter \\
Indicates that the elements are compared with each other; the former is more important than the latter \\
Indicates that the importance is between the upper and lower adjacent indicators
\end{tabular}

Among them, CI is the consistency index, and the calculation formula is as follows:

$$
\mathrm{CI}=\frac{\left(\lambda_{\max }-n\right)}{w_{i}(n-1)}
$$

\section{Suitability Evaluation Results and Analysis}

5.1. Comprehensive Analysis of Environmental Suitability Evaluation for Smart Rural Tourism in a Certain Area. In order to analyze the gap in the smart rural tourism environ- ment in a certain region, according to the scores of the suitability of each smart rural tourism environment, an index of the suitability of the smart rural tourism environment in a certain region is obtained, as shown in Figure 4. Under ArcGIS 10.1, according to the smart rural tourism environmental suitability index of each administrative village, villages in a certain area are divided into three types of spaces, which are high-level areas, general-level areas, and low-level areas in order. At the same time, according to the classification of the suitability of the smart rural tourism environment of each administrative village, the spatial differentiation of the 




FIGURE 4: The environmental suitability index of smart rural tourism in a certain area.

suitability of the smart rural tourism environment in a certain area is obtained.

The spatial distribution of the comprehensive score value of the smart rural tourism environmental suitability in a certain area is relatively unbalanced and roughly presents a spatial differentiation pattern of three high-value core areas. In the neighboring areas, the villages in the area are strongly driven by the economic development of the surrounding areas, and the public service facilities and infrastructure are relatively complete, and the external accessibility is relatively high. It is suitable for the development of smart rural tourism environment construction; the villages included in the general-level area are mainly distributed in high-level areas, and the edges of higher-level areas are more radiated and driven by the economic and public facilities of the villages in high-value areas. Infrastructure and public service facilities can meet the basic living requirements of villagers, and further construction and development are needed. The value area is mainly distributed in the central and eastern regions of the county, becoming a low point for the development of a smart rural tourism environment in a certain area. The villages in this area are relatively weak in policy and economic radiation, are low in social development, and lack various infrastructures. The development conditions need to be improved urgently. At the same time, there are a total of 55 low-level regions in the low-value area, which is more than $1 / 3$ of the total number of villages, reflecting the unsatisfactory development level of the smart rural tourism environment in a certain area. Therefore, it is necessary to analyze from the inside of each subsystem to find out the reasons to reduce the regional differences in the smart rural tourism environment of a certain region and county.
5.2. Suitability Analysis of the Intelligent Rural Tourism Environment Subsystem in a Certain Area. In order to deepen the analysis of the environmental suitability of smart rural tourism in a certain area, it is necessary to analyze the scores of the natural environment subsystem, basic support subsystem, and social service subsystem that constitute the suitability of the smart rural tourism environment. Figure 5 shows the spatial type distribution index of the three subsystems of the smart rural tourism environment in a certain area.

5.2.1. Natural Environment Subsystem. The proportion of areas with high levels of natural environmental suitability is $63.4 \%$, and the proportion of low-level areas is only $11.1 \%$, which means that most of the rural natural environment in the county is suitable for the development of smart rural tourism environment construction. The areas with higher scores of rural natural environmental suitability in a certain area are mainly concentrated in the eastern part of the central part of the county, that is, the low-elevation plain area in the middle. The natural environmental suitability level of a certain area presents a circle structure space of "high in the east and low in the west." The natural environmental suitability scores of low-level areas are lower than the average of the whole district. There are 43 villages in the range, and most of them are distributed in the peripheral border areas of the county. This area is distributed in mountains and hills with large terrain fluctuations. It adds difficulty and cost to the development and construction of the smart rural tourism environment. Therefore, it is recommended to merge villages with an altitude higher than $1000 \mathrm{~m}$ and a slope greater than $30^{\circ}$ into surrounding villages suitable for construction to ensure the sustainable 




FiguRe 5: Differences in the suitability index of the smart rural tourism environment subsystem in a certain area.

development of the construction of the smart rural tourism environment. Figure 6 shows the degree of intelligentization of rural natural environment suitability in a certain area.

5.2.2. Basic Support Subsystem. Areas with a high level of suitability for rural foundation support in a certain area mainly appear in the northern, southeast, and southwestern parts of the county, and the overall spatial differentiation pattern of "outer protrusions and central depressions" appears. At the same time, its spatial differentiation characteristics are similar to those of smart villages in a certain area. There are obvious similarities in the spatial differentiation characteristics of the suitability of the tourism environment; that is, the suitability of the basic support subsystem and the suitability of the smart rural tourism environment are obviously positively correlated. Roads have strong external accessibility, and high-grade roads have a high coverage rate, have a strong driving effect on surrounding villages, and have obvious advantages in regional transportation; environmental sanitation infrastructure can cover all villages more comprehensively, which can fully meet the needs of the rural population. Its advantage is that there is still transit traffic, but the road level is low. At the same time, the environmental sanitation infrastructure is not perfect. The domestic garbage and production garbage cannot be treated in time, which can increase the promotion of environmental infrastructure and improve the basic living conditions of villagers. Villages in low-level areas are mainly distributed in the central area of the county. The transit traffic coverage in this area is low, the external accessibility is weak, and the environmental sanitation infrastructure is relatively backward, which has become a low area for the development of rural infrastructure support in a certain area. This area first needs to improve the basic living conditions of the villagers by improving the external transportation capacity and reducing the time cost to reduce the difficulty of infrastructure deployment. Figure 7 shows the degree of intelligentization of rural foundation support suitability in a certain area.

5.2.3. Social Public Service Subsystem. The suitability of rural social public service in a certain area roughly presents a spatial differentiation pattern of "high in the south and low in the north." Among them, the villages contained in the high-level area basically coincide with the scope of the high-level area of the smart rural tourism environmental suitability evaluation in a certain area. The rural social public service facilities in the area are well configured, which greatly promotes the improvement of the environmental suitability of smart rural tourism. The coverage rate of public service indicators such as educational facilities, cultural and recreational facilities, and medical security facilities in this area is relatively high, which is better than other villages. Villages in high-level areas are mostly located in the southwest of the county, and the coverage of educational facilities in the area is relatively high, but the coverage of medical security and cultural and entertainment facilities is lower than that of high-level areas. Low-level areas are mainly concentrated in the central area of the county. The coverage of villagers' fitness activity venues, cultural stations, and educational facilities in the area is all at the lowest value. At the same time, there are basically no medical insurance facilities in the villages in the area. The development of rural public services has resulted in a large difference in suitability from high-level areas. This area urgently needs to be added to the social public service facilities to improve the status quo 




FigURE 6: The degree of intelligentization of rural natural environment suitability in a certain area.

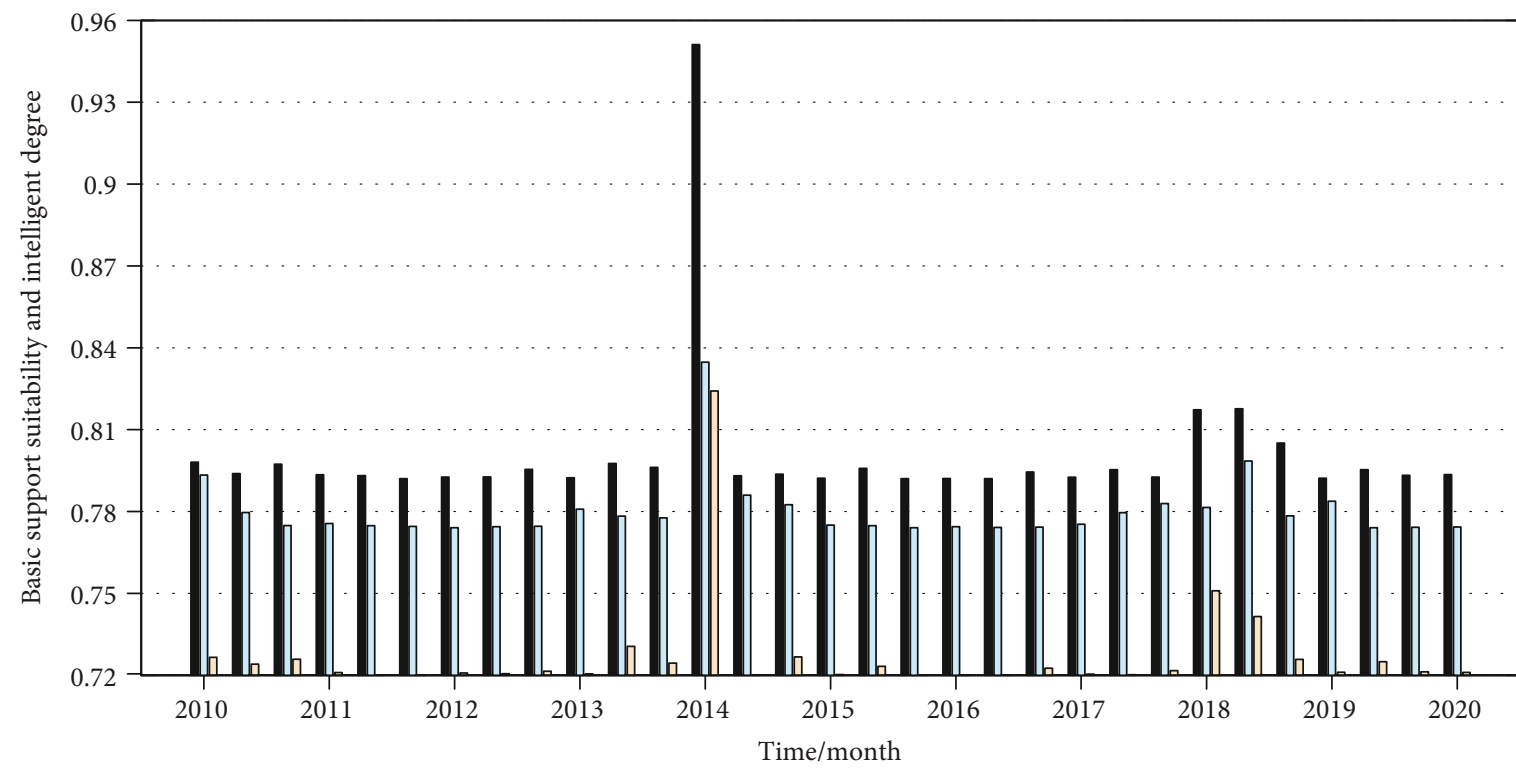
Low level area
$\square$ General level area
High level area

FIgURE 7: The degree of intelligentization of rural foundation support suitability in a certain area. 


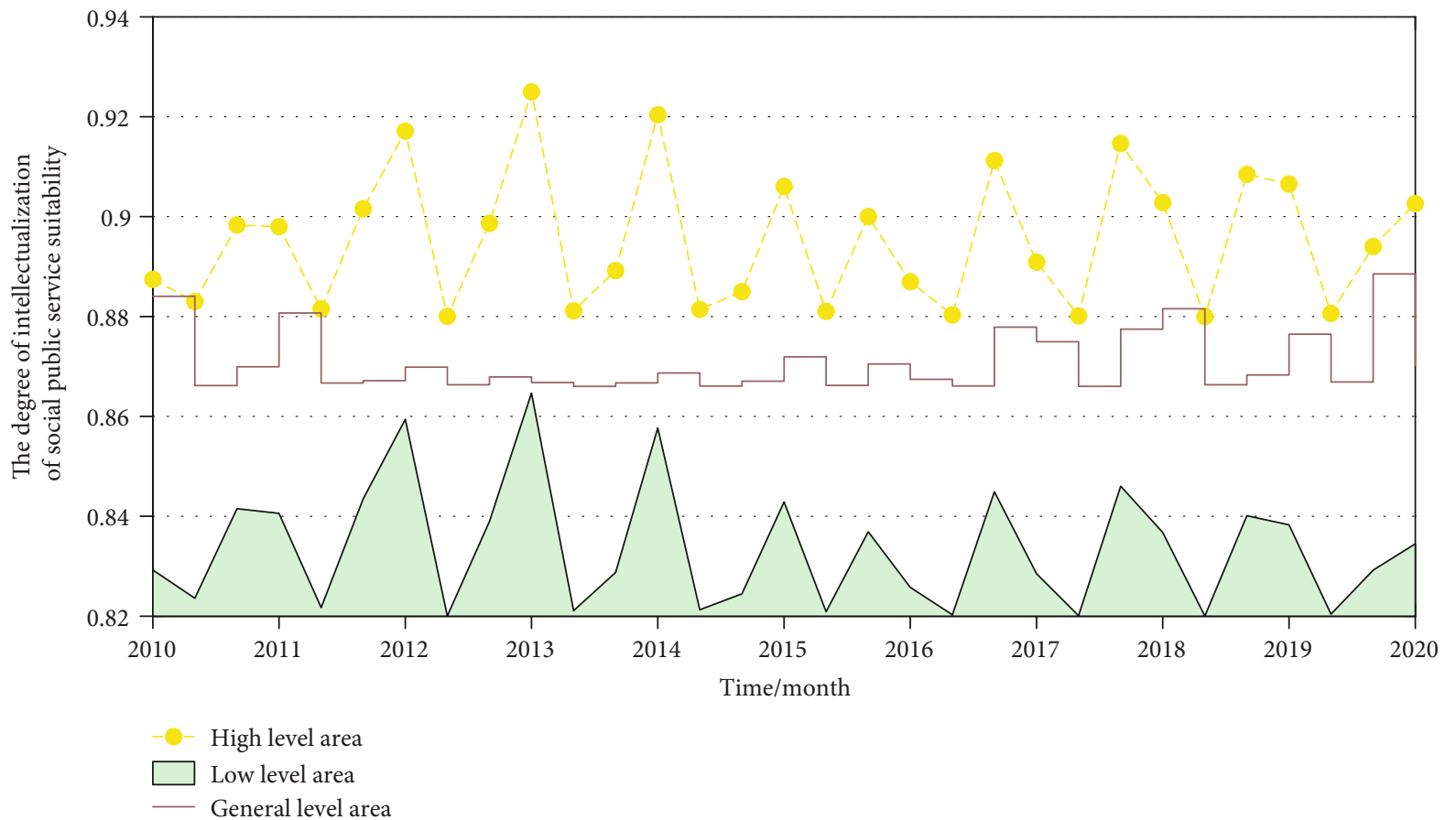

FIGURE 8: The degree of suitability and intelligence of rural social public services in a certain area.

of the suitability of rural social public service facilities. Figure 8 shows the degree of suitability and intelligence of rural social public services in a certain area.

\section{Conclusion}

With reference to the basic principles of suitability evaluation for the development and utilization of land resources, we select evaluation indicators, determine an indicator evaluation system, and construct a multifactor comprehensive evaluation model. The comprehensive weight of each evaluation index is calculated by the analytic hierarchy process, and then the suitability evaluation result is obtained after the overlay analysis and reclassification of each index data on the ArcGIS operating platform. According to the obtained adaptability evaluation results, by referring to the relevant tourism planning of a certain area, we determine the potential areas suitable for the development of rural tourism resorts, and by querying relevant data, we comprehensively measure the characteristics and actual conditions of the rural tourism resources in the potential areas. Taking villages in a certain area as the evaluation object, using the established intelligent rural tourism environmental suitability evaluation system, based on data collection and processing, we systematically assessed the development level of the smart rural tourism environmental suitability in a certain area. The results show that the overall scores of the environmental suitability of smart rural tourism in a certain area are quite different, and the smart rural tourism environmental suitability scores are divided into 3 types of hierarchical spaces. At the same time, there is a certain difference in the spatial distribution of the suitability scores of the subindices of various subsystems. Among them, the suitability of the smart rural tourism environment is significantly related to economic development and the construction of infrastructure support facilities. The investment in infrastructure construction plays an important role in improving the suitability of the smart rural tourism environment. As a complex giant system, the smart rural tourism environment involves numerous indicators and complex relationships. There is no clear standard for the optimal state of the smart rural tourism environment. This study may be insufficient in the selection of evaluation indicators. The calculation and the combination of indicators still require more precise and scientific methods. In addition, how to strengthen the coordination construction between the strength indicators and the weakness indicators, and ultimately to coordinate the sustainable development of the smart rural tourism environment, needs to be further updated and improved. It is believed that with the deepening of research, the theory and technical methods of the evaluation of the suitability of the smart rural tourism environment will be gradually improved, which can play a more scientific guiding role in the sustainable development of the smart rural tourism environment.

\section{Data Availability}

The data used to support the findings of this study are available from the corresponding author upon request.

\section{Conflicts of Interest}

The authors declare that they have no known competing financial interests or personal relationships that could have appeared to influence the work reported in this paper. 


\section{Acknowledgments}

This work was supported by the Heilongjiang University of Foreign Languages preresearch project "Research on the realization mechanism and path of rural economy and cultural sharing under the background of global tourism" (project number: lwyu-2021-10).

\section{References}

[1] A. Majnouni-Toutakhane, M. E. Ramazani, and S. Sheikholeslam, "Recognition and analysis of the key factors of rural development in Iran with futures studies approach," Journal of Rural Development, vol. 39, no. 4, pp. 569-593, 2021.

[2] Ö. Saribaş and C. Demir, "Sensory studies as a multidisciplinary research field and its use in tourism research: a bibliometric analysis on tourism literature," Turizm Akademik Dergisi, vol. 7, no. 1, pp. 269-283, 2020.

[3] D. Akbari, S. N. Omrani Sigaroodi, and M. Akbari, "Locating tourist accommodation centers using ANP-VIKOR model (case study of Rodsar County)," Application of Geography Information System and Remote Sensing in Planning, vol. 11, no. 2, pp. 26-36, 2020.

[4] F. Minaei, M. Minaei, I. Kougias, H. Shafizadeh-Moghadam, and S. A. Hosseini, "Rural electrification in protected areas: a spatial assessment of solar photovoltaic suitability using the fuzzy best worst method," Renewable Energy, vol. 176, pp. 334-345, 2021.

[5] P. Martí, C. García-Mayor, and L. Serrano-Estrada, "Taking the urban tourist activity pulse through digital footprints," Current Issues in Tourism, vol. 24, no. 2, pp. 157-176, 2021.

[6] I. M. Wardana, I. P. G. Sukaatmadja, N. W. Ekawati, N. N. K. Yasa, I. P. Astawa, and M. Setini, "Policy models for improving ecotourism performance to build quality tourism experience and sustainable tourism," Management Science Letters, vol. 11, no. 2, pp. 595-608, 2021.

[7] Z. Tao, J. Guanghui, M. Wenqiu et al., "Dying villages to prosperous villages: a perspective from revitalization of idle rural residential land (IRRL)," Journal of Rural Studies, vol. 84, pp. 45-54, 2021.

[8] J. Makovníková, B. Pálka, S. Kolosta, and K. Orságová, “Application of matrix approach for evaluation and assessment the potential of recreational ecosystem service in model regions in Slovakia," Open Journal of Ecology, vol. 11, no. 4, pp. 437450, 2021.

[9] A. M. S. Brooker, J. Aversa, and R. R. Shaker, "Identifying tourist experiences in Maui, Hawaii using mobile location data," Papers in Applied Geography, vol. 6, no. 2, pp. 132-150, 2020.

[10] D. Rina, R. F. Mauliddy, and N. Insani, "Gili Genting Island ecotourism assessment trough operational area analysis of natural tourism attractions," Jurnal SPATIAL Wahana Komunikasi dan Informasi Geografi, vol. 21, no. 1, pp. 18-28, 2021.

[11] Ç. Sabbağ and R. Arıca, "Customer to customer information production: the evaluation of customer reviews in Tripadvisor on food and beverage service providers in Adiyaman," Journal of Tourism and Gastronomy Studies, vol. 8, no. 2, pp. 729-745, 2020.

[12] Y. Wenting, Z. He, and Z. Shuying, "Sustainable development and tourists' satisfaction in historical districts: influencing factors and features," Journal of Resources and Ecology, vol. 12, no. 5, pp. 669-681, 2021.
[13] F. Xu, N. Nash, and L. Whitmarsh, "Big data or small data? A methodological review of sustainable tourism," Journal of Sustainable Tourism, vol. 28, no. 2, pp. 144-163, 2020.

[14] R. Ghanbari, B. Sobhani, M. Aghaee, A. oshnooei nooshabadi, and V. Safarianzengir, "Monitoring and evaluation of effective climate parameters on the cultivation and zoning of corn agricultural crop in Iran (case study: Ardabil province)," Arabian Journal of Geosciences, vol. 14, no. 5, pp. 1-11, 2021.

[15] A. J. Kadhim and J. I. Naser, "Toward electrical vehicular ad hoc networks: E-VANET," Journal of Electrical Engineering \& Technology, vol. 16, no. 3, pp. 1667-1683, 2021.

[16] M. Jelokhani-Niaraki, "Collaborative spatial multicriteria evaluation: a review and directions for future research," International Journal of Geographical Information Science, vol. 35, no. 1, pp. 9-42, 2021.

[17] S. J. Alavion and A. Taghdisi, "Rural E-marketing in Iran; modeling villagers' intention and clustering rural regions," Information Processing in Agriculture, vol. 8, no. 1, pp. 105133, 2021.

[18] E. Yaacoub and M. S. Alouini, "A key 6G challenge and opportunity-connecting the base of the pyramid: a survey on rural connectivity," Proceedings of the IEEE, vol. 108, no. 4, pp. 533$582,2020$.

[19] P. Sokolnikova, P. Lombardi, B. Arendarski et al., "Net-zero multi-energy systems for Siberian rural communities: a methodology to size thermal and electric storage units," Renewable Energy, vol. 155, pp. 979-989, 2020.

[20] Z. Wang, L. Tang, J. S. Huang, H. Shi, and L. Bian, "Reconstruction and application of flooding routing algorithm for smart street light over wireless sensor networks," International Journal of Internet Protocol Technology, vol. 13, no. 1, pp. 9-17, 2020. 